\title{
The Estimation of Arginine
}

\author{
By H. ROSENBERG, A. H. ENNOR AND J. F. MORRISON \\ Department of Biochemistry, John Curtin School of Medical Research, The Australian National University, \\ Canberra, A.C.T. Australia
}

(Received 29 November 1955)

Arginine has been estimated by precipitation as the picrate and flavianate complexes, enzymically by the action of arginase followed by the estimation of the urea formed, microbiologically and colorimetrically (cf. Block \& Bolling, 1947). The colorimetric method developed by Sakaguchi $(1925 a, b)$ has been most widely used. This method relies upon the formation of a red-coloured complex produced by arginine and other monosubstituted guanido compounds in the presence of $\alpha$-naphthol and alkaline hypobromite or hypochlorite. Although this method will qualitatively detect small quantities of arginine, it is unreliable quantitatively, as evidenced by the large number of modifications that have been suggested, and which have been reviewed recently by Gómez \& Marenzi (1953).

A colorimetric method for the estimation of both mono- and di-substituted guanidines was introduced by Eggleton, Elsden \& Gough (1943). These compounds give a red-coloured complex with diacetyl and $\alpha$-naphthol in alkaline solution. The authors found that monosubstituted guanidines such as arginine and glycocyamine produced only one-ninth of the colour given by asymmetrically disubstituted guanidines such as creatine. This observation has been confirmed by Ennor \& Stocken (1953) and by Roche, Thoai \& Hatt (1954). Although this method is less sensitive than the Sakaguchi method, it is simpler and more reliable.

This paper describes a modification of the above reaction. When the colour is developed in the presence of $n$-propanol and an increased concentration of $\alpha$-naphthol, the sensitivity of the method for monosubstituted guanidines is equal to that previously obtained with disubstituted guanidines. Thus it is possible to estimate arginine in amounts ranging from 10 to $100 \mu \mathrm{g}$.

\section{EXPERIMENTAL}

\section{Materials}

n-Propanol. $n$-Propanol was purified by distillation after refluxing over $\mathrm{NaOH}$ and $\mathrm{Al}$ powder.

$\alpha$-Naphthol. The commercial material was light brown in colour and was purified by two steam-distillations from $2 \mathrm{~N}-\mathrm{H}_{2} \mathrm{SO}_{4}$. It was then dried in vacuo at $60^{\circ}$, and dissolved in $n$-propanol to give a $25 \%(\mathrm{w} / \mathrm{v})$ solution, and stored in a dark bottle at $-20^{\circ}$.
Stock diacetyl solution. A stock diacetyl solution (about $1 \%$ ) was prepared from dimethylglyoxime as described by Walpole (1911).

Arginine. Arginine hydrochloride was recrystallized from $0.4 \mathrm{~N}-\mathrm{HCl}$ (cf. Greenberg, 1951), and its purity was checked by $\mathrm{N}$ analysis.

Other guanido compounds. Guanidine (A.R.) was used. Creatine was recrystallized as described by Hunter (1928). Glycocyamine (guanidoacetic acid) was recrystallized from water. $N$-Ethylguanidoacetic acid (negmine) was kindly supplied by Dr M. D. Armstrong (seo Ennor, Rosenberg \& Armstrong, 1955). $\alpha$-Guanidopropionic acid, $\beta$-guanidopropionic acid and $\beta$-guanidoethylsulphonic acid (taurocyamine) were prepared by guanylation with $S$-ethylthiourea of alanine, $\beta$-alanine and taurine respectively, as described by Brand \& Brand (1942) for the preparation of glycocyamine. 1:2-Diguanidoethane, 1-guanidoethane and 2-guanidoethanol were prepared from ethylenediamine, ethylamine and ethanolamine respectively by the method of Schenck \& Kirchhof (1926). They were recrystallized several times and their purity was checked by elementary analysis. Streptomycin sulphate (Glaxo) was used as supplied. Solutions of these compounds of the required concentration were made up and adjusted to $\mathrm{pH}$ 7-7.5. They were stored at $-10^{\circ}$.

Proteins employed for arginine assays were: crystalline insulin (Boots); crystalline bovine-plasma albumin (Armour and Co. Ltd.): edestin (British Drug Houses Ltd.); pure sheet Winterthur gelatin (by the courtesy of Kodak A/Asia Ltd.) and pure standard wool cloth (a gift from Dr D. Waterhouse, C.S.I.R.O., Canberra, Australia).

\section{Methods}

Protein hydrolysates. The method adopted for the hydrolysis of proteins was as follows: $100 \mathrm{mg}$. of protein and $2.0 \mathrm{ml}$. of $20.5 \%(\mathrm{w} / \mathrm{v}) \mathrm{HCl}$ were placed in a sealed tube and heated at $110^{\circ}$. The periods of heating varied and will be referred to specifically in the text. Under the conditions used, humin production was insignificant. The hydrolysates were washed out of the tubes and made to volume. Nitrogen and arginine were estimated on the hydrolysates after neutralization and appropriate dilution.

Nitrogen estimation. Duplicate samples of hydrolysates were ashed with the digestion mixture described by Campbell \& Hanna (1937). The digests were made to suitable volumes, and samples were distilled in the apparatus of Markham (1942). The distillate was collected in a boric acid buffer containing a mixed indicator (Conway \& O'Malley, 1942) and titrated with 0.01 N-HCl.

Colour estimation. The optical density of the red-coloured solution was estimated in a Hilger Spekker absorptiometer (fitted with a dark chamber for housing the cells) with an Ilford spectrum-green filter (no. 604; abs. max., $535 \mathrm{~m} \mu$.). 


\section{RESULTS}

In the early experiments designed to increase the sensitivity of the $\alpha$-naphthol-diacetyl method for the estimation of arginine it was found that, if the final concentration of $\alpha$-naphthol was increased from 0.2 to $1.0 \%$, the intensity of the resultant colour was increased by a factor of about $\mathbf{1 \cdot 5}$. However, a more marked increase was observed after the addition of alcohols in concentrations of $20 \%(v / v)$. The effect of a number of alcohols on the colour intensity produced by arginine in the $\alpha$-naphthol-diacetyl reaction has been investigated, and it is clear (Table 1) that all the alcohols examined caused an increase in the optical density and that $n$-propanol and ethanol were the most effective. Alcohols with longer carbon chains than those listed were tested, but even in the presence of ethanol did not mix with the aqueous phase in the presence of the other solutes.

A comparison was then made of the effect of both ethanol and propanol on the optical density over a range of concentrations. The results (Table 2)

Table 1. Effect of alcohols on the colour intensity produced by arginine in the $\alpha$-naphthol-diacetyl reaction

Tubes contained $50 \mu \mathrm{g}$. of arginine, $1 \mathrm{ml}$. of a $1: 20$ dilution of stock diacetyl solution, $2 \mathrm{ml}$. of a $5 \%(w / v)$ solution of $\alpha$-naphthol in $5 \mathrm{~N}-\mathrm{NaOH}$ and $2 \mathrm{ml}$. of the alcohol. Total volume, $10 \mathrm{ml}$. All readings were taken 20 min. after addition of reagents.

\begin{tabular}{lc}
\multicolumn{1}{c}{ Alcohol } & $E$ \\
None & $0 \cdot 092$ \\
Methanol & $\mathbf{0 \cdot 1 9 2}$ \\
Ethanol & $\mathbf{0 . 2 7 3}$ \\
Ethylene glycol & $\mathbf{0 . 1 8 8}$ \\
n-Propanol & $\mathbf{0 . 3 5 0}$ \\
isoPropanol & $\mathbf{0 \cdot 1 4 8}$ \\
tert.-Butanol & $\mathbf{0 . 1 3 0}$
\end{tabular}

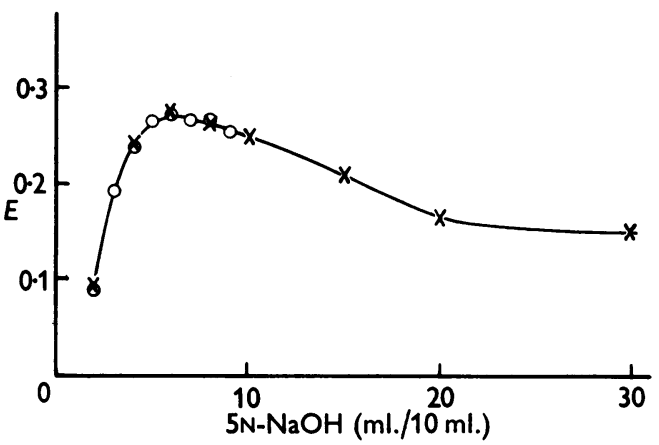

Fig. 1. Effect of $\mathrm{NaOH}$ concentration on the intensity of colour produced by arginine. Tubes contained $0.2 \mu \mathrm{mole}$ of arginine, $2 \mathrm{ml}$. of developing reagent containing $5 \%$ (w/v) $\alpha$-naphthol and $2.5 \%$ stock diacetyl in $n$-propanol and $\mathrm{NaOH}$ as indicated. The results of two separate experiments $(x$ and $O)$ are shown.

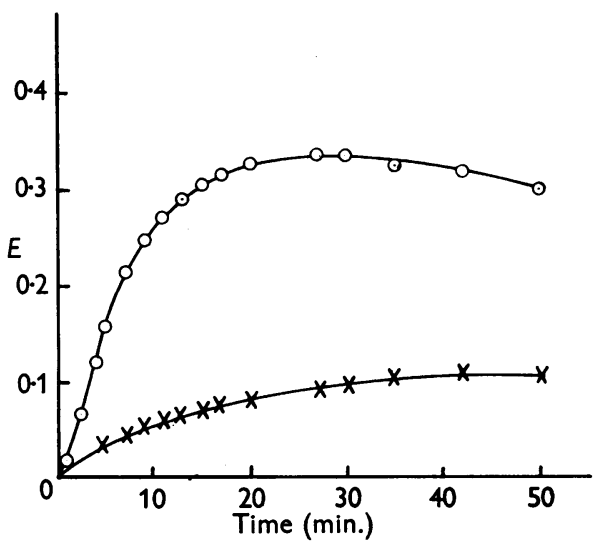

Fig. 2. Time-development curves for the colours produced by $0.3 \mu \mathrm{mole}$ of arginine. $\bigcirc$, Standard procedure; $x$, as before with propanol omitted.

Table 2. Effect of various concentrations of ethanol and n-propanol on the intensity of colour produced by $25 \mu g$. of arginine

For other conditions see Table 1.

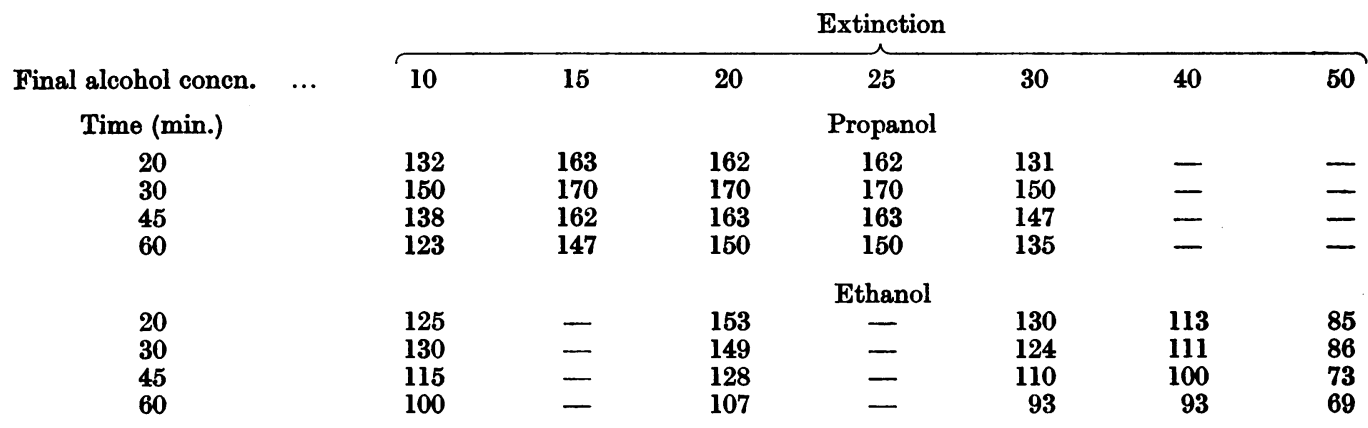


indicate that $n$-propanol is more effective than ethanol at all concentrations investigated. The stability of the colour also tends to be higher with $n$ propanol. The optimum concentration of $n$-propanol lies between 15 and $25 \%$, and a concentration of $20 \%$ was chosen for all subsequent experiments.

Effect of $\alpha$-naphthol concentration on the colour intensity. In view of the considerable increase in colour intensity due to the presence of $n$-propanol it was of interest to determine whether, under the now altered conditions, the $\alpha$-naphthol concentration could be reduced from the $1 \%$ level, but it was found that reduction of the concentration resulted in a nearly proportional reduction of the colour intensity. The effect of higher concentrations of $\alpha$-naphthol was not tested, because even at the $1 \%$ level there was significant discoloration in the blanks. $\alpha$-Naphthol was therefore used at a final concentration of $1.0 \%(\mathrm{w} / \mathrm{v})$.

Effect of $\mathrm{NaOH}$ concentration. In the initial experiments $1 \mathrm{ml}$. of $5 \mathrm{~N}-\mathrm{NaOH}$ was added per tube (vol. $10 \mathrm{ml}$.). The optimum amount of $\mathrm{NaOH}$ necessary for the reaction was determined in the presence of optimum amounts of the other reagents. It will be seen (Fig. 1) that the optimum amount was about $0.6 \mathrm{ml}$. of $5 \mathrm{~N}-\mathrm{NaOH} / 10 \mathrm{ml}$. In practice $1 \mathrm{ml}$. of $3 \mathrm{~N}-\mathrm{NaOH}$ was used.

Standard method. The final procedure adopted for the estimation of arginine was as follows: A developing solution was prepared by mixing $20 \mathrm{ml}$. of $25 \%(\mathrm{w} / \mathrm{v}) \alpha$-naphthol in $n$-propanol with $2.5 \mathrm{ml}$. of stock diacetyl solution and diluting the mixture to $100 \mathrm{ml}$. with $n$-propanol.

Graduated test tubes (10 ml.) containing the samples for arginine estimation and $1 \mathrm{ml}$. of

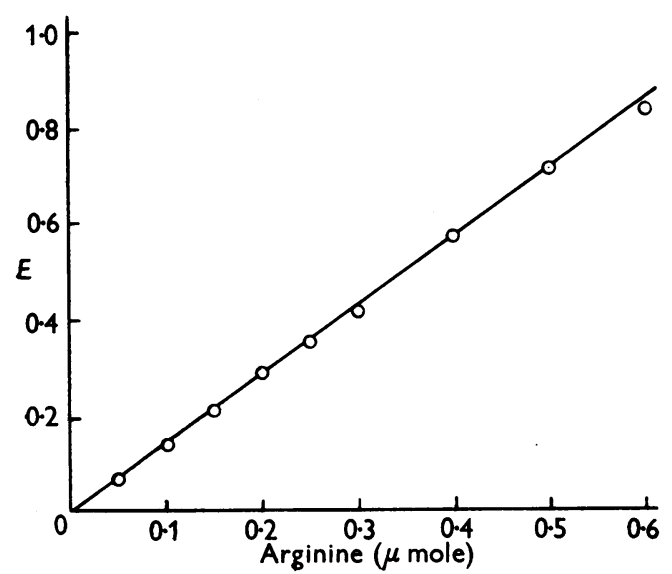

Fig. 3. Relationship between the concentration of arginine and the colour intensity. Tubes contained arginine in varying amounts as indicated, $2 \mathrm{ml}$. of the developing reagent and $1 \mathrm{ml}$. of $3 \mathrm{~N}-\mathrm{NaOH}$ in a final volume of $10 \mathrm{ml}$.
$3 \mathrm{~N}-\mathrm{NaOH}$ were arranged with a blank tube preceding each set of four tubes. The developing solution $(2 \mathrm{ml}$.) was then added to each tube at 30 sec. intervals. The contents were made to $10 \mathrm{ml}$. with water and mixed by shaking. Readings were commenced 20-30 min. after the first addition, tubes being read at 30 sec. intervals. This procedure will be referred to as the standard method.

Time-course of colour development. The timecolour development curves for $0.3 \mu$ mole of arginine in the standard method and without $n$-propanol are given in Fig. 2. It appears that the effect of $n$-propanol is to increase both the rate of formation of the coloured complex and the colour intensity.

Relationship between the concentration of arginine and the intensity of colour. Fig. 3 shows that the colour intensity is proportional to the concentration of arginine between the limits of $0.05-0.6 \mu$ mole (8-100 $\mu \mathrm{g}$.).

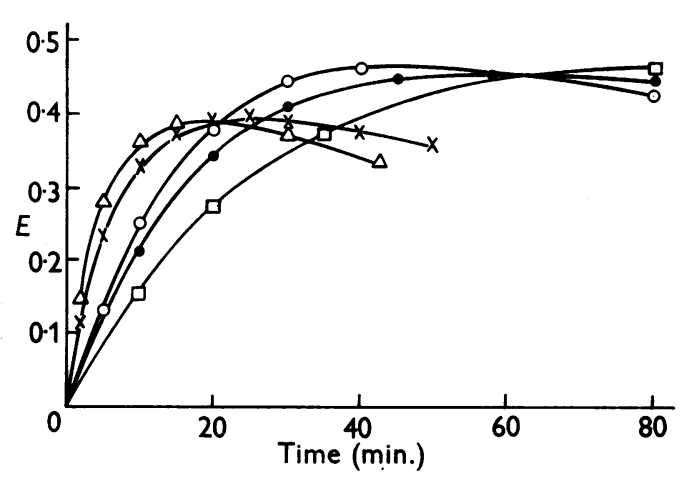

Fig. 4. Effect of temperature on the rate of formation and breakdown of the coloured arginine complex. The reaction mixture was the same as described in Fig. 3. Development temperatures: $\square, 10^{\circ} ; 0,15^{\circ} ; 0,18^{\circ}$; $\times, 25^{\circ} ; \triangle, 30^{\circ}$.

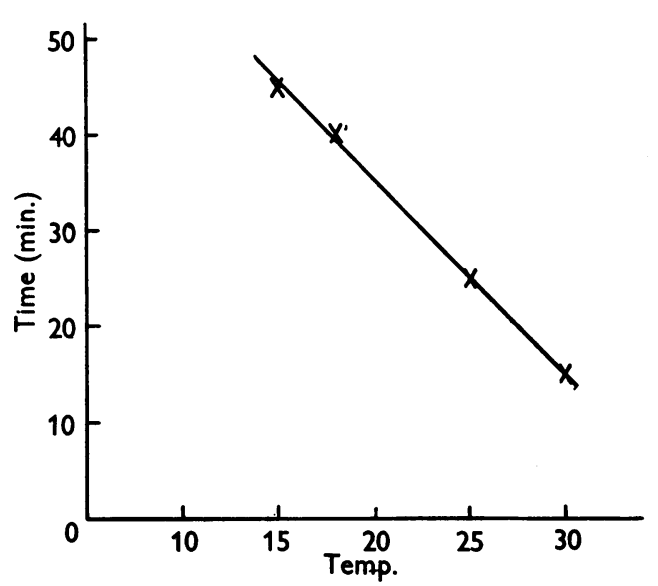

Fig. 5. Relation between temperature and time required to reach maximum colour development. (For details see Fig.4.) 
Effect of temperature on the development of colour. The effect of temperature on the time taken to reach maximal colour intensity and on the stability of the coloured complex has also been investigated (Fig. 4). It will be seen that the maximum colour obtained with a given quantity of arginine tends to increase with decreasing temperature, and that at the same time there is a considerable increase in the stability of the colour. If the time required to reach maximum colour development is plotted against temperature (Fig. 5), a straight line is obtained which can be used as an indication of the development time if maximum sensitivity is required.

Linearity at various stages of colour development. A study was made of the relationship between the colour intensity at various stages of the reaction at $20^{\circ}$ and the concentration of arginine. The results (Fig. 6) indicate that a direct proportionality holds between these quantities both before and after the development of maximum colour. (Maximum colour development is reached in $35 \mathrm{~min}$. at $20^{\circ}$.) Thus provided standards are used, readings can be taken over a wide range of times after the addition of the reagents. However, for maximum sensitivity colours should be read at a time depending upon the temperature, as shown in Fig. 5.

Application of the reaction to the estimation of other guanido compounds. In view of the satisfactory results obtained with arginine the sensitivity of the method for related compounds was determined. Table 3 lists the molecular extinction coefficients for various substituted guanidines and for free guanidine. The extinctions are given for $0.2 \%(w / v)$ and $1.0 \%(w / v)$ final concentrations of $\alpha$-naphthol in aqueous solutions and for $1.0 \%$ $(\mathrm{w} / \mathrm{v}) \alpha$-naphthol in $20 \%(\mathrm{v} / \mathrm{v}) n$-propanol. It will be seen that the effect of increasing the $\alpha$-naphthol concentration is to increase the colour intensity in all cases. On the other hand, the addition of $n$ propanol decreases the colour intensity produced by the asymmetrically disubstituted guanidines, creatine and negmine, but increases the intensity of colour of the monosubstituted guanidines (and of free guanidine) three- to ten-fold. The result is that the molecular extinction coefficients of the latter group in the presence of $n$-propanol are raised to the level of the former in aqueous solution. It is necessary to note that the molecular extinctions have been obtained under optimum conditions for arginine. The possibility exists that the optimum conditions for each compound may differ and that under ideal conditions higher molecular extinctions may result. It will be noted that the moecular extinction of diguanidoethane is approximately twice that of either guanidoethane or guanidoethanol. This is in accordance with the results of Dumazert \& Poggi (1939) who, with the
Sakaguchi reaction, found that the molecular extinction of diguanido compounds was approximately double that of monoguanidines.

Estimation of streptomycin. Streptomycin, which contains two guanido groups/molecule, produced a colour under the standard conditions for the estimation of arginine, and could be estimated in quantities ranging from 0.05 to $1 \mu$ mole. The molecular extinction in the standard reaction was found to be $13.3 \times 10^{3}$, which is comparable with the values obtained for monoguanido compounds (cf. Table 3).

Reproducibility of results. The amount of scatter in the standard procedure was checked by carrying out a series of estimations involving thirty-two tubes each containing $50 \mu \mathrm{g}$. of arginine. A mean value for $E$ of 0.385 was obtained. The standard deviation was $0 \cdot 022$.

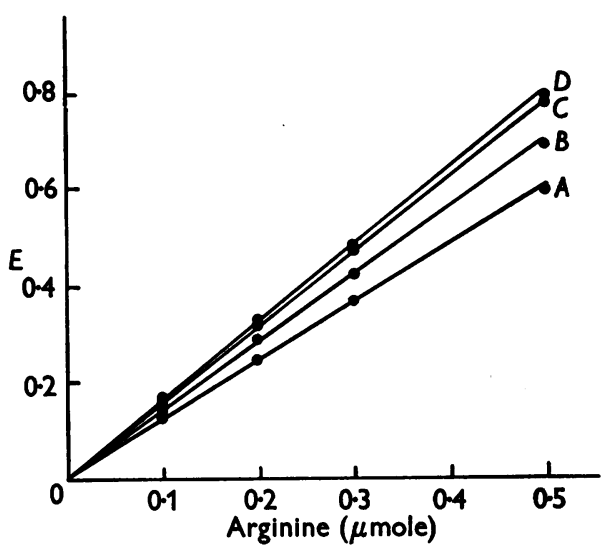

Fig. 6. Relation between the arginine concentration and the colour intensity at various stages of colour development. (For details see Fig. 3.) Colour densities were estimated at $15(A), 22(B), 30(C)$ and $40(D) \mathrm{min}$.

Table 3. Molecular extinction coefficients of various substituted guanidines

Column $C$, standard procedure; column $B$, same, with propanol omitted; column $A$, as $B$, but $\alpha$-naphthol decreased to $0 \cdot 2 \%$.

\begin{tabular}{|c|c|c|c|}
\hline \multirow[b]{2}{*}{ Compound } & \\
\hline & $\boldsymbol{A}$ & $\boldsymbol{B}$ & $C$ \\
\hline Creatine & $16 \cdot 1$ & $23 \cdot 5$ & $17 \cdot 7$ \\
\hline Negmine & $13 \cdot 5$ & $19 \cdot 8$ & $14 \cdot 2$ \\
\hline Glycocyamine & $2 \cdot 5$ & 3.7 & $15 \cdot 6$ \\
\hline$\alpha$-Guanidopropionic acid & $2 \cdot 9$ & $4 \cdot 5$ & $13 \cdot 3$ \\
\hline$\beta$-Guanidopropionic acid & $2 \cdot 7$ & $3 \cdot 7$ & $16 \cdot 9$ \\
\hline Taurocyamine & $2 \cdot 6$ & $3 \cdot 7$ & $16 \cdot 7$ \\
\hline Arginine & $\mathbf{2 \cdot 6}$ & $\mathbf{3 . 7}$ & $15 \cdot 7$ \\
\hline Guanidine & $1 \cdot 8$ & $2 \cdot 0$ & $19 \cdot 2$ \\
\hline 1:2-Diguanidoethane & - & - & $24 \cdot 6$ \\
\hline 1-Guanidoethane & 一 & - & $13 \cdot 6$ \\
\hline 2-Guanidoethanol & - & - & $13 \cdot 6$ \\
\hline
\end{tabular}


Estimation of the arginine content of some proteins. The arginine content of a number of proteins hydrolysed by the procedure described above (Methods) has been determined. The results (Table 4) are compared with those selected as best values by Block \& Bolling (1947). It is clear that the method is applicable to the estimation of the arginine content of proteins.

The effect of prolonged hydrolysis on the values obtained for the arginine content of protein was

Table 4. Arginine content of various proteins

All values are given as $\mathrm{mg}$. of arginine/16 mg. of total $\mathrm{N}$. The samples of hydrolysates used in the estimation contained an equivalent of $0 \cdot 5-2.0 \mathrm{mg}$. of the original protein.

\begin{tabular}{lccc} 
Protein & $\begin{array}{c}\text { Time of } \\
\text { hydrolysis } \\
(\mathrm{hr} .)\end{array}$ & $\begin{array}{c}\text { Found by } \\
\text { analysis }\end{array}$ & $\begin{array}{c}\text { Best values } \\
\text { (Block \& } \\
\text { Bolling, 1947) }\end{array}$ \\
Serum albumin & 40 & $6 \cdot 0$ & $5 \cdot 2$ \\
Gelatin & 40 & $7 \cdot 5$ & $7 \cdot 6$ \\
Insulin & 48 & 3.3 & 3.4 \\
Wool & 18 & 10.0 & 10.0 \\
\hline
\end{tabular}

Table 5. Arginine content of insulin and edestin

Both proteins were hydrolysed in $20.5 \% \mathrm{HCl}$ at $110^{\circ}$ for periods shown below.

\begin{tabular}{|c|c|c|}
\hline \multirow{2}{*}{$\begin{array}{l}\text { Time } \\
\text { (hr.) }\end{array}$} & \multicolumn{2}{|c|}{ Arginine $(\mathrm{mg} . / 16 \mathrm{mg}$. of $\mathrm{N})$} \\
\hline & Insulin & Edestin \\
\hline 0 & - & 8.9 \\
\hline 0.25 & $2 \cdot 1$ & 11.6 \\
\hline 0.5 & $2 \cdot 3$ & $13 \cdot 8$ \\
\hline 1.0 & 2.5 & $15 \cdot 4$ \\
\hline 1.5 & $2 \cdot 7$ & $15 \cdot 4$ \\
\hline 2.0 & $2 \cdot 8$ & 15.6 \\
\hline $2 \cdot 5$ & 2.9 & $16 \cdot 1$ \\
\hline 3.0 & $2 \cdot 9$ & $16 \cdot 3$ \\
\hline $4 \cdot 5$ & - & 16.7 \\
\hline $6 \cdot 0$ & $3 \cdot 2$ & 16.6 \\
\hline $12 \cdot 0$ & $3 \cdot 3$ & 17.0 \\
\hline 18 & $3 \cdot 3$ & - \\
\hline 24 & $3 \cdot 3$ & $17 \cdot 2$ \\
\hline 48 & 3.3 & $16 \cdot 3$ \\
\hline 72 & 3.2 & - \\
\hline 100 & $3 \cdot 2$ & - \\
\hline
\end{tabular}

determined. A number of samples of insulin and edestin were hydrolysed in sealed tubes at $110^{\circ}$ for periods ranging from $15 \mathrm{~min}$. to $100 \mathrm{hr}$. The arginine and $\mathrm{N}$ contents of the hydrolysates were then estimated. The results are shown in Table 5 . It is seen that the arginine value was maximal for both proteins after hydrolysis for $24 \mathrm{hr}$. and that with insulin it did not fall after $100 \mathrm{hr}$.

Recovery of added arginine from protein hydrolysates. In order to ascertain that other components of the hydrolysates did not exert any inhibitory effect on the colour reaction, recovery studies were carried out (Table 6). It is clear from the satisfactory recoveries that under these conditions there is no interference by other amino acids.

Inhibition of the reaction by various compounds. The inhibition of the reaction by some other amino acids, ammonia and several buffers is shown in Table 7. It will be seen that the amino acids and similarly the peptide glycylglycine as well as aminotrishydroxymethylmethane inhibited the reaction at concentrations of $1-2 \times 10^{-2} \mathrm{M}$. At this level the molar concentration of the amino acids exceeded that of the arginine present by a factor of about 700 .

\section{DISCUSSION}

Diacetyl and $\alpha$-naphthol react in alkaline solution with guanidines possessing a free guanido $-\mathrm{NH}_{2}$ group. It has long been realized that under comparable conditions the colour produced by asymmetrically disubstituted guanidines of the general formula $\mathrm{H}_{2} \mathrm{~N}$.C(:NH). $\mathrm{NR}_{1} \mathrm{R}_{2}$ (e.g. creatine) is five to ten times as intense as that produced by the monosubstituted guanidines.

The present work has shown that the sensitivity of the reaction of the latter group of guanidines can be greatly increased if the reaction is carried out in the presence of any one of a number of simple alcohols, preferably $n$-propanol. The precise nature of the effect of alcohols on the reaction is difficult to define, particularly as little or no knowledge exists as to the nature of the reaction

Table 6. Recovery of arginine added to various protein hydrolysates

\begin{tabular}{|c|c|c|c|c|c|}
\hline \multirow[b]{2}{*}{$\begin{array}{c}\text { Protein } \\
\text { hydrolysed }\end{array}$} & \multicolumn{4}{|c|}{ Arginine ( $\mu \mathrm{g} . / \mathrm{ml})}$. & \multirow[b]{2}{*}{$\begin{array}{c}\text { Recovery } \\
(\%)\end{array}$} \\
\hline & $\begin{array}{c}\text { Present } \\
\text { originally }\end{array}$ & Added & Found & Recovered & \\
\hline Insulin & 50.9 & $\begin{array}{l}\mathbf{2 5 \cdot 0} \\
\mathbf{5 0 \cdot 0}\end{array}$ & $\begin{array}{l}75 \cdot 6 \\
98 \cdot 4\end{array}$ & $\begin{array}{l}24 \cdot 7 \\
47 \cdot 9\end{array}$ & $\begin{array}{l}99 \\
96\end{array}$ \\
\hline Albumin & $51 \cdot 5$ & $\begin{array}{l}25 \cdot 0 \\
50 \cdot 0\end{array}$ & $\begin{array}{r}74 \cdot 6 \\
101 \cdot 0\end{array}$ & $\begin{array}{l}25 \cdot 5 \\
51 \cdot 9\end{array}$ & $\begin{array}{l}102 \\
104\end{array}$ \\
\hline Wool & $45 \cdot 1$ & $\begin{array}{l}25 \cdot 0 \\
50 \cdot 0\end{array}$ & $\begin{array}{l}69 \cdot 7 \\
94 \cdot 5\end{array}$ & $\begin{array}{l}24 \cdot 6 \\
49 \cdot 4\end{array}$ & $\begin{array}{l}98 \\
99\end{array}$ \\
\hline Gelatin & $30 \cdot 2$ & $\begin{array}{l}25 \cdot 0 \\
50 \cdot 0\end{array}$ & $\begin{array}{l}54 \cdot 9 \\
80 \cdot 7\end{array}$ & $\begin{array}{l}24 \cdot 5 \\
50 \cdot 5\end{array}$ & $\begin{array}{r}98 \\
101\end{array}$ \\
\hline
\end{tabular}


Table 7. Inhibition by various compounds of the colour produced by $50 \mu \mathrm{g}$. of arginine in the standard procedure

\begin{tabular}{|c|c|c|}
\hline Compound & $\begin{array}{l}\text { Concn. } \\
\text { (M) }\end{array}$ & $\begin{array}{c}\text { Inhibition } \\
(\%)\end{array}$ \\
\hline Glycine & $\begin{array}{l}0.01 \\
0.02\end{array}$ & $\begin{array}{l}34 \\
55\end{array}$ \\
\hline Tyrosine & $\begin{array}{l}0.01 \\
0.02\end{array}$ & $\begin{array}{l}13 \\
22\end{array}$ \\
\hline Tryptophan & $\begin{array}{l}0.01 \\
0.02\end{array}$ & $\begin{array}{l}21 \\
28\end{array}$ \\
\hline Histidine & $\begin{array}{l}0.01 \\
0.02\end{array}$ & $\begin{array}{l}12 \\
15\end{array}$ \\
\hline Ammonia & $0 \cdot 1$ & 0 \\
\hline Glycylglycine & $\begin{array}{l}0.001 \\
0.01\end{array}$ & $\begin{array}{l}15 \\
81\end{array}$ \\
\hline Aminotrishydroxymethylmethane & $\begin{array}{l}0.001 \\
0.01\end{array}$ & $\begin{array}{r}3 \\
58\end{array}$ \\
\hline Phosphate & $0 \cdot 01$ & 0 \\
\hline Glycerophosphate & $0 \cdot 01$ & 0 \\
\hline$N$-Ethylmorpholine & $0 \cdot 01$ & 0 \\
\hline
\end{tabular}

which occurs between a guanido compound, $\alpha$ naphthol and diacetyl. It is apparent, however, from the results that alcohols increase the speed with which the various components react to produce the red-coloured complex, and in addition have a stabilizing effect on the colour.

The present method was developed after the failure to obtain reliable results for the estimation of arginine by the method of Sakaguchi $(1925 a, b)$. The original method, as well as some modifications, including those by Sakaguchi (1950, 1951), were tried, but in no case were the results reproducible nor were linear graphs obtained. With solutions of unknown arginine content difficulties arose because the latter must be roughly determined in order to add the correct amount of hypobromite. The timing between the addition of hypobromite and urea was critical, and errors were frequently introduced by condensate appearing on the exterior walls of the cells and bubbles of gas on the interior. The colours, moreover, were not stable. These and other objections have been expressed by a number of other authors, notably by Macpherson (1942).

The new method does not suffer from the disadvantages of the Sakaguchi method and is easier to carry out. The tubes can be prepared with the sample, and the $\mathrm{NaOH}$ added before the commencement of the actual estimation, which then involves only a single addition of the developing mixture to each tube. The colour intensity is proportional to the concentration of arginine over a wide range and the sensitivity is as high as that claimed by Sakaguchi (1950). The method can be used for the estimation of any guanido compound alone, but it will not differentiate between two such compounds if present together.

The investigations have been concerned chiefly with estimation of arginine and to a lesser extent with other monoguanidines, but some experiments have been carried out on the estimation of streptomycin, for which the method described seems suitable. Dumazert \& Poggi (1939) showed that simple diguanido compounds such as arcaine and synthaline reacted with the Sakaguchi reagents in such a way as to give a molecular extinction twice that of a monoguanidine. A similar result has been obtained with diguanidoethane, using the method described above. It was therefore expected that since streptomycin contains two guanido groups it would, using the present method, yield a molecular extinction double that found with monoguanidines. The molecular extinction found however was close to that of these latter compounds and it would thus seem possible that one of the groups is masked by the glycoside side chain.

The values for the arginine content of proteins, as compared with those quoted in the literature and the satisfactory recoveries of added arginine, indicate that the method is suitable for the estimation of arginine in protein material.

The results obtained with the prolonged hydrolysis of proteins are not in agreement with some published work. Thus, Hunter \& Dauphinee (1929-30) claimed that the amount of arginine decreased with the time of hydrolysis, and Roche \& Blanc-Jean (1940) estimated that with edestin $35 \%$ of the total arginine was lost on hydrolysis for $24 \mathrm{hr}$. with $\mathrm{HCl}$. No such losses have been obtained in this work with insulin and edestin.

The experiments concerning the inhibitory action of some compounds on the colour reaction show that some of the commonly used buffers, namely glycine, glycylglycine, histidine and aminotrishydroxymethylmethane inhibit at concentrations at which they are likely to be employed. It is therefore necessary to avoid the use of these buffers in systems in which guanidines are to be estimated by this colour reaction. Amino acids in high concentrations also produce marked inhibitions; however, these concentrations are greatly in excess of the combined concentrations of other amino acids in protein hydrolysates appropriately diluted for arginine estimation.

If the estimation of arginine is to be carried out on trichloroacetic acid extracts of tissues the colour should be allowed to develop in the dark or in artificial light. This is necessary because of the blue colour which would otherwise develop from the interaction of sodium trichloroacetate and $\alpha$ naphthol (cf. Eggleton et al. 1943).

In contrast to the Sakaguchi procedure the present method is not inhibited by ammonia. 


\section{SUMMARY}

1. A method for the colorimetric estimation of arginine has been described.

2. The applicability of the method for the estimation of other guanido compounds, including streptomycin, has been demonstrated.

3. The method was shown to be suitable for the estimation of the arginine content of proteins.

4. The advantages of the method, as compared with that of Sakaguchi, have been discussed.

\section{REFERENCES}

Block, R. J. \& Bolling, D. (1947). The Amino Acid Composition of Proteins and Foods, lst ed. 2nd printing. Springfield, Illinois: Charles C. Thomas.

Brand, E. \& Brand, F. C. (1942). Org. Synth. 22, 59.

Campbell, W. R. \& Hanna, M. I. (1937). J. biol. Chem. 119, 1.

Conway, E. J. \& O'Malley, E. (1942). Biochem. J. 36, 655.

Dumazert, C. \& Poggi, R. (1939). Bull. Soc. Chim. biol., Paris, 21, 1381.

Eggleton, P., Elsden, S. R. \& Gough, N. (1943). Biochem. J. 37, 526.
Ennor, A. H., Rosenberg, H. \& Armstrong, M. D. (1955). Nature, Lond., 175, 120.

Ennor, A. H. \& Stocken, L. A. (1953). Biochem. J. 55, 310.

Gómez, C. J. \& Marenzi, A. D. (1953). Pubs. inst. invest. microquim. Univ. nacl. litoral (Rosario, Arg.), 17, 94. Cited by Chem. Abstr. (1954), 48, $11523 \mathrm{f}$.

Greenberg, D. M. (1951). Amino Acids and Proteins, p. 244. Springfield, Illinois: Charles C. Thomas.

Hunter, A. (1928). Creatine and Creatinine. London: Longmans, Green and Co. Ltd.

Hunter, A. \& Dauphinee, J. A. (1929-30). J. biol. Chem. $85,627$.

Macpherson, H. T. (1942). Biochem. J. 36, 59.

Markham, R. (1942). Biochem. J. 36, 790.

Roche, J. \& Blanc-Jean, G. (1940). C.R. Acad. Sci., Paris, 210, 681.

Roche, J., Thoai, N. \& Hatt, J. L. (1954). Biochim. biophys. Acta, 14, 71.

Sakaguchi, S. (1925a). J. Biochem., Tokyo, 5, 25.

Sakaguchi, S. (1925b). J. Biochem., Tokyo, 5, 133.

Sakaguchi, S. (1950). J. Biochem., Tokyo, 37, 231.

Sakaguchi, S. (1951). J. Biochem., Tokyo, 38, 91.

Schenck, M. \& Kirchhof, H. (1926). Hoppe-Seyl. Z. 155, 306.

Walpole, G. S. (1911). J. Physiol. 42, 301.

\title{
The Short-Term Effect of Pituitary Growth Hormone on the Catabolism of Fat in the Liver
}

\author{
By A. L. GREENBAUM \\ Department of Biochemistry, University College, London
}

(Received 6 October 1955)

Rats treated with anterior-pituitary growth hormone undergo a change in metabolic pattern in favour of a retention of nitrogen and water and a loss of fat (Lee \& Schaffer, 1934; Young, 1945; Greenbaum, 1953). In a previous communication it was shown that injections of growth hormone caused profound changes in the catabolism of fat, particularly during the first 3 days of treatment (Greenbaum \& McLean, 1953). At short time intervals after treatment $(6 \mathrm{hr}$.) there was an inhibition of fat oxidation and an increase in the endogenous respiration in liver-tissue suspensions from treated rats as compared with similar preparations from control rats; while at $12 \mathrm{hr}$. this pattern was reversed, i.e. an inhibition of the endogenous respiration and increase in fat catabolism was found. At periods of $24 \mathrm{hr}$. or longer after the initiation of treatment there appeared to be no difference between control and experimental animals, although there is little doubt that the energy metabolism of the treated animals was based largely on fat and that of the controls on the usual mixture of carbohydrate, protein and fat (Greenbaum, 1953). It seemed possible from these results that the liver responded rapidly to growth hormone but that the effect was essentially shortterm, and that the longer-term effect of growth hormone in stimulating fat catabolism was possibly effected in the extrahepatic tissues. It was also suggested that the two-phase picture of fat metabolism obtained in the livers of treated rats in the first $24 \mathrm{hr}$. of growth-hormone treatment might be explained on the basis of a pancreatropic effect of growth hormone. This would result in a release of insulin over the first few hours, and this insulin would then produce its characteristic effect, an inhibition of fat oxidation. At the longer time interval the secretion of insulin would have declined and the growth hormone effect would then become obvious.

The present communication describes experiments which tend to show that some of the shortterm effects of growth hormone are indeed due to insulin, and that the full effect of growth hormone 